\title{
Pengaruh Kompetensi Profesional Guru Terhadap Kualitas Proses Pembelajaran Pada Paket Keahlian Administrasi Perkantoran Di SMK Negeri 1 Gowa
}

\author{
Muhammad Darwis, Ulfa Dwi Batari, Risma Niswaty, Maya Kasmita, Aris \\ Baharuddin \\ Universitas Negeri Makassar \\ Email: darwis.matta@gmail.com
}

(Diterima: 17-Juli-2018; di revisi: 14-Agustus-2018; dipublikasikan: 30-Desember-2018)

\begin{abstract}
ABSTRAK
Penelitian ini bertujuan untuk mengetahui Pengaruh Kompetensi Profesional Guru terhadap Kualitas Proses Pembelajaran pada Paket Keahlian Administrasi Perkantoran di SMK Negeri 1 Gowa. Penelitian ini merupakan penelitian kuantitatif yang menunjukkan pengaruh variabel $\mathrm{X}$ terhadapa variabel $\mathrm{Y}$. populasi dalam penelitian ini adalah berjumlah 100 orang. Sampel dalam penelitian ini sebesar 50 orang. Teknik pengumpulan data yang digunakan adalah angket, observasi, wawancara dan dokumentasi. Sedangkan teknik analisis datanya menggunakan analisis statistik deskriptif serta teknik analisis statistic inferensial menggunakan analisis regresi linear sederhana. Hasil penelitian menunjukkan bahwa, kompetensi profesional guru di SMK Negeri 1 Gowa berada pada kategori sangat baik dengan tingkat persentase 88 persen, untuk kualitas proses pembelajaran di SMK Negeri 1 Gowa tergolong dalam kategori sangat baik dengan tingkat persentase sebesar 81,8 persen. Hal ini dapat dibuktikan dengan hasil analisis product moment sebesar 0,452 yang berarti tingkat hubungan dalam kategori sedang. Dapat disimpulkan bahwa ada Pengaruh Kompetensi Profesional Guru terhadap Kualitas Proses Pembelajaran pada paket Keahlian Administrasi Perkantoran di SMK Negeri 1 Gowa.
\end{abstract}

Kata kunci: Kompetensi, Profesional Guru, Kualitas Proses Pembelajaran

\begin{abstract}
This study aims to determine the Effect of Teacher Professional Competence on the Quality of Learning Processes in Office Administration Expertise Packages at Gowa 1 State Vocational School. This research is a quantitative study which shows the effect of $X$ variables on $Y$ variables. The population in this study is 100 people. The sample in this study was 50 people. Data collection techniques used were questionnaires, observations, interviews and documentation. While the data analysis technique uses descriptive statistical analysis and inferential statistical analysis techniques using simple linear regression analysis. The results showed that the professional competence of teachers in Gowa 1 State Vocational High School was in a very good category with a percentage level of 88 percent, for the quality of the learning process in Gowa 1 State Vocational High School categorized as very good with a 81.8 percent percentage level. This can be proven by the results of product moment analysis of 0.452 which means the level of relations in the medium category. It can be concluded that there is the Effect of Teacher Professional Competence on the Quality of Learning Processes in the Office Administration Expertise package at Gowa 1 State Vocational School.
\end{abstract}

Keywords: Competence, Teacher Professionals, Quality of Learning Processes.

Copyright (C 2018 Universitas Negeri Makassar. This is an open access article under the CC BY license (http://creativecommons.org/licenses/by/4.0/) 


\author{
106 Jurnal Administrare: Jurnal Pemikiran Ilmiah dan Pendidikan Administrasi Perkantoran \\ Vol. 5, No. 2, Juli - Desember 2018, Hal 105-112
}

\title{
PENDAHULUAN
}

Pendidikan adalah salah satu hal yang paling penting bagi kehidupan kita (Jamaluddin, Salam, Yunus, \& Akib, 2017). Pendidikan sebagai wahana yang sangat strategis dalam meningkatkan kualitas sumber daya manusia yang mempunyai nilai strategis bagi kelangsungan peradaban manusia di dunia. Jika pendidikan merupakan salah satu instrumen utama pengembangan SDM, tenaga kependidikan memiliki tanggung jawab untuk mengemban tugas itu(Akib, Guntur, \& Salam, 2016; Saggaf, Aras, et al., 2018; Saggaf, Akib, Salam, Baharuddin, \& Kasmita, 2018). Guru bertugas untuk mengajarka pengetahuan kepada peserta didik. Tidak hanya mendidik berupa penyampaian teori, tetapi juga dituntut memberikan bekal pengetahuan informasi yang menyajikan pengetahuan. Guru tidak hanya sekedar mengetahui materi yang akan diajarkan, tetapi juga harus memahaminya secara luas dan mendalam. Seorang guru harus memiliki kualifikasi, kompetensi dan dedikasi yang tinggi dalam menjalankan tugasnya (Amirkhanova et al., 2015; Canaleta, Vernet, Vicent, \& Montero, 2014; Kelemen, 2012; KulpaPuczyńska, 2014; Loh \& Liew, 2016; Runhaar, Konermann, \& Sanders, 2013).

Guru profesional menjadi salah satu hal penting dalam proses pembelajaran(Amanda, Salam, \& Saggaf, 2017). Kualitas proses pembelajaran juga bergantung pada guru yang memiliki kompetensi profesional yang mendukung. Kompetensi profesional guru sangat dibutuhkan dalam proses pembelajaran agar menghasilkan suasana kelas yang menyenangkan. Hal ini dapat memotivasi siswa dalam belajar dan meningkatkan prestasi belajar siswa. Karena guru yang profesional tidak hanya sekedar mengajar, tetapi mampu melaksanakann strategi pembelajaran dan menyajikan materi dengan baik dan menyenangkan yang tidak hanya berorientasi kepada ketuntasan belajar, tetapi pada proses tumbuh kembang potensi peserta didik yang meliputi aspek kogitif, efektif dan psikomotorik.

Kulitas proses pembelajaran merupakan salah satu titik tolak ukur yang dapat menentukan berhasil atau tidaknya proses pembelajaran (Salam, Zunaira, \& Niswaty, 2016). Namun, perlu diketahui bahwa ukuran berkualitas atau tidaknya suatu sekolah itu relatif, karena tolak ukur yang digunakan akan terus mengalami perubahan sesuai dengan perubahan zaman. Seorang pendidik yang dapat menerapkan pembelajaran aktif, inovatif, lingkungan, kreatif, efektif dan menarik sangat diperlukan agar pembelajaran bisa berkualitas dan relevan terhadap kebutuhan masyarakat dan dapat menciptakan peserta didik sebagai generasi masa depan yang berkualitas. Pendidik hendaknya menyadari dan intropeksi diri dengan mengedapankan pentingnya profesional dalam pembelajaran dan perlu melihat inovasi terhadap materi pembelajaran yang berkualitas, serta media pembelajaran yang berkualitas.

\section{METODE}

Metode penelitian yang digunakan dalam penelitian ini adalah Deskriktif Kuantitatif dengan jenis penelitian korelasional yang mampu memberikan informasi yang akurat mengenai pengaruh kompetensi profesional guru terhadap kualitas proses pembelajaran pada paket keahlian administrasi perkantoran di SMK Negeri 1 Gowa. Penelitian ini akan mengkaji hipotesis dan mengadakan interpretasi pengaruh variabel independen kompetensi profesional 
guru terhadap variabel dependen kualitas proses pembelajaran. Untuk mengukur variabel dalam penelitian ini, digunakan angket berskala Likert yang akan diisi oleh responden sesuai dengan indikator variabel.Adapun populasi dalam penelitian ini adalah peserta didik kelas XI Administrasi Perkantoran sebanyak 100 peserta didik, dengan menggunakan teknik sampling incidental dan menarik sampel sebanyak 50\% dengan tingkat kesalahan 5\%. Pengumpulan data dalam penelitian ini menggunakan teknik angket, wawancara, observasi dan dokumentasi. Teknik analisis yang digunakan dalam penelitian ini adalah teknik analisis statistik deskriptif dan teknik analisis inferensial yang bertujuan untuk mengkaji variabel penelitian.

\section{HASIL PENELITIAN DAN PEMBAHASAN}

\section{Kompetensi Profesional Guru}

Hasil penelitian ini menunjukkan tingkat kompetensi profesional guru pada paket keahlian administrasi perkantoran di SMK Negeri 1 Gowa berada pada kategori sangat baik. Hal ini didukung oleh indikator menguasai landasan pendidikan, menguasai bahan pengajaran, menyusun program pengajaran, menilai hasil dan proses pembelajaran yang telah dilaksanakan. Untuk lebih jelasnya, di bawah ini akan diuraikan keempat indikator tersebut yaitu:

\section{Menguasai Landasan Pendidikan}

Guru profesional harus menguasai landasan pendidikan agar dapat melakukan pembelajaran dengan baik dan tepat serta efesien. Hasil penelitian menunjukkan bahwa tingkat penguasaan landasan pendidikan pada guru paket keahlian administasi perkantoran di SMK Negeri 1 Gowa berada pada kategori sangat baik. Hal ini dukung oleh guru yang selalu menyampaikan tujuan pendidikan sehingga peserta didik dapat memahami apa tujuan pendidikan, guru juga mampu menjalankan fungsi sekolah dan masyarakat sehingga peserta didik dapat belajar dan juga mengikuti guru untuk menjalankan fungsinya pada masyarakat, guru pun menyampaikan prinsip-prinsip psikologi pendidikan sehingga peserta didik dapat memahami apa saja prinsip psikologi pedidikan.

\section{Menguasai Bahan Pengajaran}

Guru harus benar-benar memahami apa yang akan diajarkan kepada peserta didik agar saat proses pembelajaran sedang berlangsung peserta didik tidak salah kaprah. Hasil penelitian menunjukkan bahwa tingkat penguasaan bahan pengajaran pada guru paket keahlian administrasi perkantoran berada pada kategori sangat baik. Hal ini didukung oleh guru menguasai bahan pengajaran dalam proses pembelajaran sehingga guru bisa tepat sasaran saat proses pembelajara, guru melakukan penghayatan bagi siswa apabila sudah mencapai target pembelajaran, dan guru memahami materi yang diajarkan sehingga pada saat proses pembelajaran materi yang guru sampaikan dengan mudah dipahami oleh peserta didik. 
108 Jurnal Administrare: Jurnal Pemikiran Ilmiah dan Pendidikan Administrasi Perkantoran Vol. 5, No. 2, Juli - Desember 2018, Hal 105-112

\section{Menyusun Program Pengajaran}

Hasil penelitian menunjukkan bahwa tingkat penyusunan program pengajaran pada guru paket keahlian administrasi perkantoran berada pada kategori sangat baik. Hal ini didukung oleh guru menyampaikan tujuan pembelajaran sehingga peserta didik mengetahui apa tujuan pembelajaran yang sedang dipelajari, guru menggunakan media pembelajaran yang sesuai sehingga peserta dapat dengan mudah memahami dan menangka pembelajaran, guru menggunakan strategi belajar mengajar yang baik sehingga pelajaran mampu dipahami oleh peserta didik. Serta guru wajib mengikuti RPP yang telah ditentukan.

\section{Menilai hasil dan proses pembelajaran yang telah dilaksanakan}

Hasil penelitian menunjukkan bahwa tingkat penilaian hasil dan proses pembelajaran yang telah dilaksanakan pada guru paket keahlian administrasi perkantoran berada pada kategori sangat baik. Hal ini didukung oleh guru menilai hasil belajar sehingga peserta didik bisa lebih termotivasi apabila hasil belajarnya diberi nilai, dan guru menilai proses pembelajaran yang telah dilaksanakan sehingga guru juga bisa mengetahui pemahaman peserta didiknya.

Hasil penelitian tersebut sejalan dengan pendapat Usman dalam Rusdiana dan Heryati, kompetensi profesional guru secara spesifik dapat dilihat dari indikator berikut.

a. Menguasai landasan pendidikan, yaitu mengenal tujuan pendidikan, mengenal fungsi sekolah dan masyarakat, serta mengenal prinsip-prinsip psikologi pendidikan;

b. Menguasai bahan pengajaran, yaitu menguasai bahan pengajaran kurikulum pendidikan dasar dan menengah, menguasai bahan penghayatan;

c. Menyusun program pengajaran, yaitu menetapkan tujuan pembelajaran, memilih dan mengembangkan strategi belajar mengajar, memilih media pembelajaran yang sesuai, memilih dan memanfaatkan sumber belajar, melaksanakan program pengajaran, menciptakan iklim belajar mengajar yang tepat, mengatur ruangan belajar, mengelolah interaksi belajar mengajar;

d. Menilai hasil dan proses pembelajaran yang telah dilaksanakan, dalam hal ini peserta didik bisa lebih termotivasi apabila hasil belajarnya diberi nilai. Selain itu, guru juga bisa mengetahui pemahaman peserta didiknya.

Berdasarkan keempat indikator tersebut, dapat dikatakan bahwa yang memiliki kategori yang sangat baik untuk variabel kompetensi profesional guru pada paket keahlian administrasi perkantoran di SMK Negeri 1 Gowa adalah indikator menilai hasil dan proses pembelajaran yang telah dilaksanakan dengan tingkat persentase 89 persen.

\section{Kualitas Proses Pembelajaran}

Hasil penelitian ini menunjukkan tingkat kualitas proses pembelajaran pada paket keahlian administrasi perkantoran di SMK Negeri 1 Gowa berada pada kategori sangat baik. Hal ini didukung oleh indikator strategi pembelajaran yang aktif, model pembelajaran yang 
inovatif, pembelajaran yang memanfaatkaan lingkungan sebagai sumber belajar, pembelajaran yang kreatif, pembelajaran yang efektif, dan pembelajaran yang menarik.

\section{Strategi Pembelajaran yang Aktif}

Hasil penelitian menunjukkan bahwa tingkat strategi pembelajaran yang aktif yang dilakukan oleh guru administrasi perkantoran berada pada kategori sangat baik. Hal ini didukung juga oleh hasil guru membiarkan peserta didik aktif dan terlibat dalam proses belajar mengajar serta membuat peserta didik mampu menemukan konsep atau karya baru. Model Pembelajaran yang Inovatif

\section{Pembelajaran yang Memanfaatkan Lingkungan sebagai Sumber Belajar}

Hasil penelitian menunjukkan bahwa tingkat pembelajaran yang memanfaatkan lingkungan sebagai sumber belajar yang dilakukan oleh guru administrasi perkantoran berada pada kategori baik. Hal ini didukung oleh guru mewujudkan kecintaan peserta didik terhadap lingkungan disekitarnya dengan mengajarkan menjada kebersihan lingkungan serta memotivasi peserta didik untuk belajar sambil menikmati kecintaan dan keunikan alam dibuktikan dengan kondisi sekolah yang cukup bersih dan hijau.

\section{Pembelajaran yang Kreatif}

Hasil penelitian menunjukkan bahwa tingkat pembelajaran kreatif yang dilakukan oleh guru administrasi perkantoran berada pada kategori baik. Hal ini didukung oleh guru mampu memecahkan masalah dengan ide-ide atau gagasan baru dan kreatif dan menggunakan metode belajar yang kreatif serta tidak monoton disetiap pertemuan.

\section{Pembelajaran yang Efektif}

Hasil penelitian menunjukkan bahwa tingkat pembelajaran efektif yang dilakukan oleh guru administrasi perkantoran berada pada kategori sangat baik. Hal ini didukung oleh guru melakukan pembelajaran yang menghasilkan belajar yang bermanfaat dan berfokus pada peserta didik dan melakukan kegiatan belajar mengajar yang dapat membangkitkan semangat dalam proses belajar. Pembelajaran yang Menarik. Hasil penelitian menunjukkan bahwa tingkat pembelajaran menarik yang dilakukan oleh guru administrasi perkantoran berada pada kategori baik. Hal ini didukung oleh guru menciptakan suasana kelas yang tidak membosankan seperti melakukan game disela-sela pembelajaran untuk mengembalikan semangat peserta didik yang mulai bosan. Serta menciptakan suasana kelas yang menarik dengan cara-cara yang menyenangkan.

Hasil penelitian tersebut sejalan dengan pendapat Uno dan Mohamad, ada enam strategi pembelajaran yang dapat diterapkan guru dalam kegiatan pembelajaran, yaitu:
a. Strategi Pembelajaran yang Aktif;
b. Model Pembelajaran yang Inovatif;
c. Pembelajaran yang memanfaatkaan Lingkungan sebagai Sumber Belajar; 
110 Jurnal Administrare: Jurnal Pemikiran Ilmiah dan Pendidikan Administrasi Perkantoran Vol. 5, No. 2, Juli - Desember 2018, Hal 105-112

d. Pembelajaran yang Kreatif;

e. Pembelajaran yang Efektif; dan

f. Pembelajaran yang Menarik.

Berdasarkan keenam indikator tersebut, dapat dikatakan bahwa yang memiliki kategori yang sangat baik untuk variabel kualitas proses pembelajaran pada paket keahlian administrasi perkantoran di SMK Negeri 1 Gowa adalah indikator strategi pembelajaran yang aktif dengan tingkat persentase 88 persen.

\section{Pengaruh Kompetensi Profesional Guru terhadap Kualitas Proses Pembelajaran}

Berdasarkan hasil analisis dapat diketahui bahwa korelasi product moment yang menunjukkan rhitung $(0,468)$ lebih besar dibandingkan rtabel $(0,279)$. Maka hasil penelitian menunjukkan bahwa terdapat pengaruh yang signifikan antara kompetensi profesional guru terhadap kualitas proses pembelajaran pada paket keahlian administrasi perkantoran di SMK Negeri 1 Gowa. Hal ini berarti hipotesis yang diajukan yaitu "diduga ada pengaruh antara kompetensi profesional guru terhadap kualitas proses pembelajaran pada paket keahlian administrasi perkantoran di SMK Negeri 1 Gowa", dinyatakan diterima dengan tingkat pengaruh sedang.

Kompetensi profesional guru merupakan salah satu hal yang harus dikembangkan dan ditingkatkan dalam dunia pendidikan. Keberhasilan setiap peserta didik dimasa depan ditentukan oleh kualitasnya. Sementara kualitas seseorang ditetukan oleh pendidikan dan pengetahuan yang didapatkan. Karena itulah, guru yang memiliki kompetensi profesional sangat dibutuhkan dalam menentukan kualitas proses pembelajaran demi menciptakan generasi yang berkualitas pula.

Kompetensi profesional guru di SMK Negeri 1 Gowa cukup berpengaruh dalam meningkatkan kualitas proses pembelajaran. Dengan kompetensi yang memadai maka peserta didik akan turut termotivasi dan menghasilkan kualitas diri yang baik pula. Baik tidaknya kualitas proses pembelajaran sangat ditentukan oleh kompetensi profesional guru. Jika kompetensi profesional guru baik dan terus ditingkatkan maka akan memberikan dampak positif terhadap kualitas proses pembelajaran, namun sebaliknya jika kompetensi profesional guru tidak baik dan tidak ditingkatkan maka kualitas proses pembelajaran tidak akan mengalami perkembangan dalam dunia pendidikan. Dengan hal tersebut jelaslah bahwa kompetensi profesional guru merupakan salah satu hal penting yang dapat memengaruhi kualitas proses pembelajaran.

\section{SIMPULAN}

1. Kompetensi Profesional Guru (X) pada paket keahlian administrasi perkantoran di SMK Negeri 1 Gowa berada pada kategori sangat baik, hal ini ditinjau dari indikator menguasai landasan pendidikan, menguasai bahan pengajaran, menyusun program pengajaran, menilai hasil dan proses pembelajaran yang telah dilaksanakan.

2. Kualitas Proses Pembelajaran (Y) pada paket keahlian administrasi perkantoran di SMK Negeri 1 Gowa berada pada kategori sangat baik, hal ini ditinjau dari indikator strategi 
pembelajaran yang aktif, model pembelajaran yang inovatif, pembelajaran yang memanfaatkan lingkungan sebagai sumber belajar, pembelajaran yang kreatif, pembelajaran yang efektif, pembelajaran yang menarik.

3. Hasil pengujian hipotesis menunjukkan bahwa terdapat pengaruh yang positif dan signifikan antara Kompetensi Profesional Guru terhadap Kualitas Proses Pembelajaran pada Paket Keahlian Administrasi Perkantoran di SMK Negeri 1 Gowa, dengan tingkat pengaruh yang tergolong dalam kategori sedang. Hal ini ditinjau dari hasil analisis data yang telah diola dan berarti hipotesis "diduga ada pengaruh kompetensi profesional guru terhadap kualitas proses pembelajaran pada paket keahlian administrasi perkantoran di SMK Negeri 1 Gowa" dinyatakan diterima dengan tingkat pengaruh sedang.

\section{DAFTAR PUSTAKA}

Akib, H., Guntur, M., \& Salam, R. (2016). Civitas Academic Perception of "Blissful Services" for Recipient Postgraduate Program State University of Makassar, Indonesia. In International Conference on Public Organization VI (ICONPO VI) (pp. 340-350). Thammsat University, Tha Prachan Campus.

Amanda, M. O., Salam, R., \& Saggaf, S. (2017). Pengaruh Supervisi Kepala Sekolah Terhadap Kinerja Guru Di SMK Negeri 1 Bungoro Kabupaten Pangkep. In Prosiding Seminar Nasional Himpunan Sarjana Ilmu-ilmu Sosial (Vol. 2, pp. 149-154).

Amirkhanova, A., Davletkalieva, E., Muldasheva, B., Kibataeva, N., Satygliyeva, G., \& Arynhanova, E. (2015). A Model of Self-education Skills in High Education System. Procedia - Social and Behavioral Sciences, 171, 782-789. https://doi.org/https://doi.org/10.1016/j.sbspro.2015.01.192

Canaleta, X., Vernet, D., Vicent, L., \& Montero, J. A. (2014). Master in Teacher Training: A real implementation of Active Learning. Computers in Human Behavior, 31, 651-658. https://doi.org/https://doi.org/10.1016/j.chb.2013.09.020

Jamaluddin, J., Salam, R., Yunus, H., \& Akib, H. (2017). Pengaruh Budaya Organisasi terhadap Kinerja Pegawai pada Dinas Pendidikan Provinsi Sulawesi Selatan. Jurnal Ad'ministrare, $4(1), 25-34$.

Kelemen, G. (2012). Ways to Determine Students to Become Competent Teachers. Procedia Social and Behavioral Sciences, 47, 1911-1916. https://doi.org/https://doi.org/10.1016/j.sbspro.2012.06.922

Kulpa-Puczyńska, A. (2014). Teachers of Polish Vocational Schools vs. Changes in the Model of Employment and Organization of Work. Procedia - Social and Behavioral Sciences, 141, 969-975. https://doi.org/https://doi.org/10.1016/j.sbspro.2014.05.166 
112 Jurnal Administrare: Jurnal Pemikiran Ilmiah dan Pendidikan Administrasi Perkantoran Vol. 5, No. 2, Juli - Desember 2018, Hal 105-112

Loh, C. E., \& Liew, W. M. (2016). Voices from the ground: The emotional labour of English teachers' work. Teaching and Teacher Education, 55, 267-278. https://doi.org/https://doi.org/10.1016/j.tate.2016.01.016

Runhaar, P., Konermann, J., \& Sanders, K. (2013). Teachers' organizational citizenship behaviour: Considering the roles of their work engagement, autonomy and leader-member exchange. Teaching and Teacher Education, 30, 99-108. https://doi.org/https://doi.org/10.1016/j.tate.2012.10.008

Saggaf, M. S., Akib, H., Salam, R., Baharuddin, A., \& Kasmita, M. (2018). The Quality Analysis Of Academic Services.

Saggaf, M. S., Aras, M., Akib, H., Salam, R., Baharuddin, A., \& Kasmita, M. (2018). The Quality Analysis of Academic Services Based on Importance Performance Analysis (IPA).

Salam, R., Zunaira, Z., \& Niswaty, R. (2016). Meningkatkan Hasil Belajar Membuat Dokumen melalui Penggunaan Model Pembelajaran Kooperatif Tipe Make a Match (Mencari Pasangan). Jurnal Office, 2(2), 173-180. 